\title{
EU Enlargement and the New Goods Margin in Austrian Trade: Reply
}

\author{
John T. Dalton ${ }^{1}$
}

Published online: 2 August 2017

(C) Springer Science+Business Media, LLC 2017

I thank Ignacio del Rosal for his careful reading and critical comments of my recent contribution to this journal, Dalton (2017). He argues the results in Dalton (2017) overestimate the change in the new goods margin between Austria and the new entrants to the EU in 2004 due to changes in product classification.

Del Rosal rightfully points out my published results are different than an earlier version of the paper, which had similar results to the version of the paper originally submitted to this journal. The original submission used 4-digit SITC Revision 2 codes, but, at the referee's suggestion, I revised the paper with 6-digit HS codes from the ComExt Database. Unfortunately, I did not catch the problems with changing product classifications described in del Rosal's comment in my revision.

As del Rosal points out in his comments, "Changes in product classification do not have perfect solutions." He argues the best option is to use the conversion tables between different HS versions available from the United Nations Statistics Division, which I agree is a good suggestion. As someone who has worked with productlevel data repeatedly, let me also mention a practical suggestion to the researcher: use an intermediate level of aggregation, which in many cases avoids the problems associated with changing product codes at the most disaggregated level of data. The drawback to this approach is obviously that the codes are not the most disaggregated available, but it is a less cumbersome approach and less susceptible to problems associated with changing product classification. It is for this reason that I often use 4-digit SITC Revision 2 codes, as in my original submission to this journal and elsewhere (Dalton 2014).

This reply refers to the comment available at: https://doi.org/10.1007/s11079-017-9442-3.

John T. Dalton

daltonjt@wfu.edu

1 Department of Economics, Wake Forest University, Kirby Hall, Box 7505, Winston-Salem, NC 27019, USA 
Table 1 Share of Least-Traded Goods

Austrian Exports to...

Year Cyprus Czech Republic Estonia Hungary Latvia Lithuania Malta Poland Slovakia Slovenia

\begin{tabular}{lllllllllll}
\hline 1999 & 0.10 & 0.10 & 0.10 & 0.10 & 0.10 & 0.10 & 0.10 & 0.10 & 0.10 & 0.10 \\
2000 & 0.08 & 0.09 & 0.09 & 0.09 & 0.12 & 0.09 & 0.09 & 0.09 & 0.10 & 0.08 \\
2001 & 0.07 & 0.09 & 0.10 & 0.10 & 0.09 & 0.10 & 0.05 & 0.09 & 0.09 & 0.08 \\
2002 & 0.04 & 0.10 & 0.09 & 0.12 & 0.15 & 0.13 & 0.12 & 0.10 & 0.10 & 0.09 \\
2003 & 0.13 & 0.10 & 0.13 & 0.14 & 0.19 & 0.15 & 0.13 & 0.10 & 0.11 & 0.12 \\
2004 & 0.29 & 0.17 & 0.30 & 0.23 & 0.31 & 0.29 & 0.35 & 0.21 & 0.20 & 0.25 \\
2005 & 0.45 & 0.21 & 0.67 & 0.22 & 0.35 & 0.54 & 0.33 & 0.22 & 0.17 & 0.18 \\
2006 & 0.40 & 0.20 & 0.60 & 0.23 & 0.27 & 0.43 & 0.05 & 0.20 & 0.19 & 0.17 \\
2007 & 0.38 & 0.18 & 0.42 & 0.23 & 0.35 & 0.41 & 0.45 & 0.21 & 0.20 & 0.18 \\
2008 & 0.52 & 0.21 & 0.46 & 0.25 & 0.28 & 0.44 & 0.25 & 0.21 & 0.20 & 0.18 \\
2009 & 0.40 & 0.22 & 0.44 & 0.27 & 0.34 & 0.41 & 0.25 & 0.25 & 0.25 & 0.21 \\
\hline
\end{tabular}

For comparison's sake, I report the results from my original submission using 4-digit SITC Revision 2 codes in Tables 1 and 2. The magnitudes of the results are much more in line with those results presented by del Rosal. On average, the new goods account for $42 \%$ of the bilateral trade flow after EU enlargement, which is lower than the $56 \%$ reported in Dalton (2017). The timing in the growth of the share of least traded goods coincides much better with enlargement than the timing in Dalton (2017) (see, for example, Figs. 1 and 2 presented here compared with Figures 5 and 10 in Dalton (2017)). As del Rosal points out, the timing in Dalton (2017) is affected by the changes in product classification. The other main results I mention in Dalton (2017) remain the same: growth in the new goods margin is higher

Table 2 Share of Least-Traded Goods

Austrian Imports from...

Year Cyprus Czech Republic Estonia Hungary Latvia Lithuania Malta Poland Slovakia Slovenia

\begin{tabular}{lllllllllll}
\hline 1999 & 0.10 & 0.10 & 0.10 & 0.10 & 0.10 & 0.10 & 0.10 & 0.10 & 0.10 & 0.10 \\
2000 & 0.07 & 0.09 & 0.07 & 0.09 & 0.12 & 0.12 & 0.08 & 0.10 & 0.09 & 0.09 \\
2001 & 0.10 & 0.10 & 0.09 & 0.09 & 0.11 & 0.21 & 0.07 & 0.10 & 0.10 & 0.09 \\
2002 & 0.13 & 0.10 & 0.14 & 0.11 & 0.17 & 0.34 & 0.06 & 0.13 & 0.15 & 0.13 \\
2003 & 0.13 & 0.11 & 0.50 & 0.13 & 0.23 & 0.32 & 0.07 & 0.17 & 0.18 & 0.15 \\
2004 & 0.52 & 0.20 & 0.67 & 0.14 & 0.30 & 0.45 & 0.12 & 0.23 & 0.22 & 0.31 \\
2005 & 0.69 & 0.21 & 0.52 & 0.20 & 0.28 & 0.65 & 0.50 & 0.26 & 0.34 & 0.20 \\
2006 & 0.54 & 0.23 & 0.37 & 0.20 & 0.32 & 0.68 & 0.61 & 0.29 & 0.39 & 0.20 \\
2007 & 0.66 & 0.23 & 0.45 & 0.21 & 0.53 & 0.69 & 0.41 & 0.31 & 0.38 & 0.21 \\
2008 & 0.75 & 0.23 & 0.60 & 0.23 & 0.51 & 0.73 & 0.57 & 0.31 & 0.38 & 0.23 \\
2009 & 0.91 & 0.24 & 0.70 & 0.23 & 0.74 & 0.78 & 0.58 & 0.39 & 0.45 & 0.25 \\
\hline
\end{tabular}




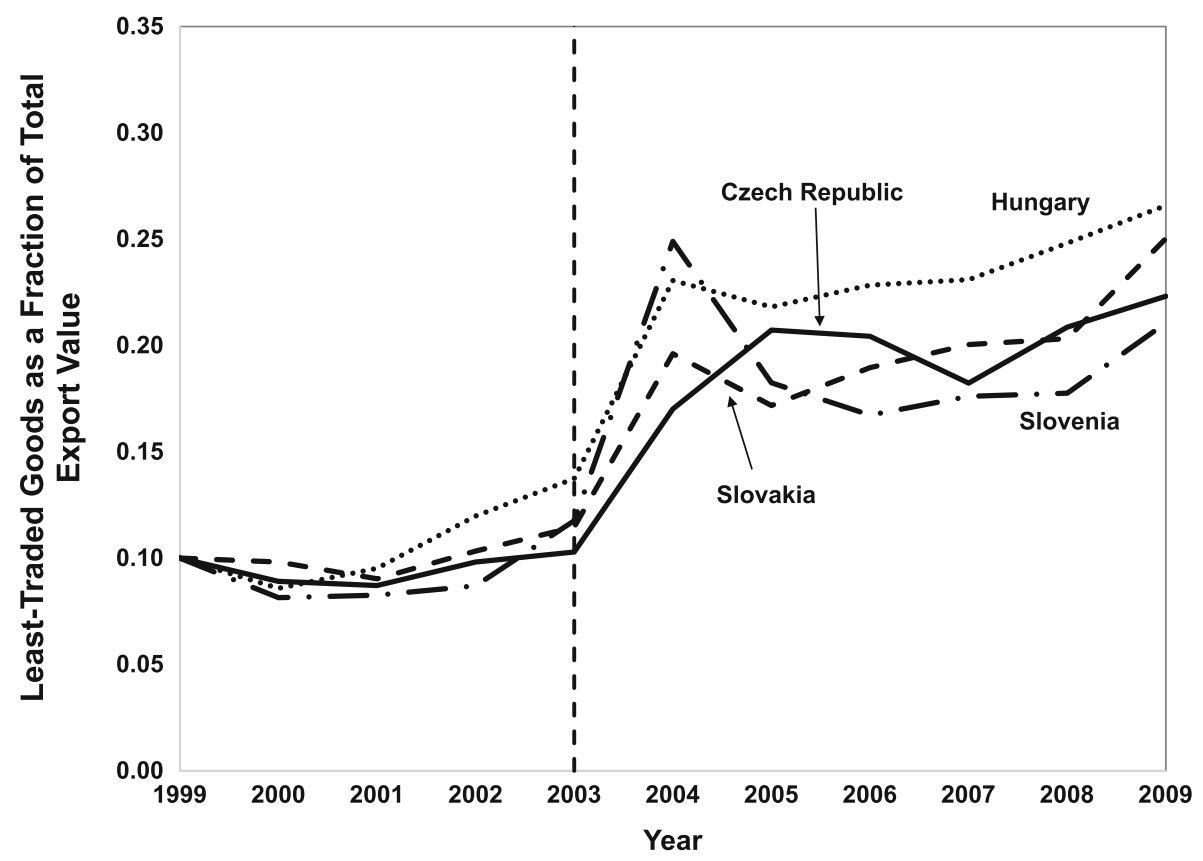

Fig. 1 Austrian Exports to Border Countries

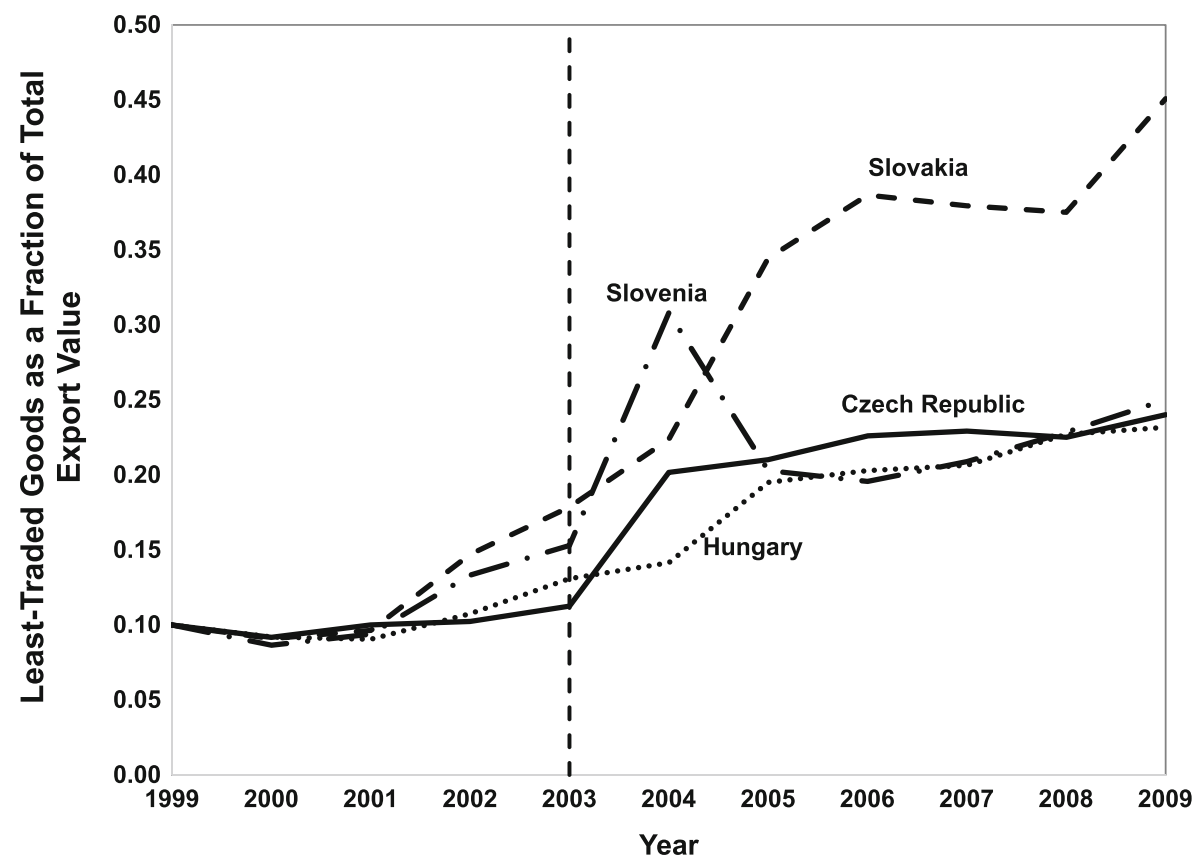

Fig. 2 Border Country Exports to Austria 
for Austrian imports from the EU expansion countries than it is for Austrian exports to these countries, and, on average, the magnitude of trade growth in the new goods margin is higher for EU entrants not sharing a border with Austria than between Austria and its immediate neighbors.

All sets of results, both from myself and del Rosal, support what I hoped would be the main point of Dalton (2017)-the new goods margin played a significant role in trade growth between Austria and the new EU entrants during the 2004 enlargement of the EU. Of course, the details matter, and I thank Ignacio del Rosal for clarifying the effects of the 2004 enlargement.

\section{References}

Dalton JT (2014) The New Goods Margin in Japanese-Chinese Trade. Jpn World Econ 31:8-13

Dalton JT (2017) EU Enlargement and the New Goods Margin in Austrian Trade. Open Econ Rev 28(1):61-78 